\title{
UK calls a halt to moves to privatize laboratories
}

[LONDON] A wave of relief tinged with irritation flowed through many British government laboratories and research organizations last week at the news that the government has, after a lengthy review, decided not to transfer them to private ownership.

Among the organizations that will remain in the public sector are the British Geological Survey, part of the Natural Environment Research Council, and the National Radiological Protection Board. The news also affects several units run by the Medical Research Council (MRC), although one the Virology Unit - is likely to be taken over by the University of Glasgow.

The decision on 37 separate laboratories represents the outcome of the most recent stage of the so-called 'prior options' review. This was launched by the Conservative government in 1993 to review all government-run laboratories and examine whether they should continue to be funded directly by the public sector.

Many scientists whose futures had been hanging in the air for many months and who had feared widespread redundancies if the privatizations had gone ahead were expressing relief at last week's news.

There was also relief within the research councils concerned. These will not now, as had been threatened, have to find large lump sums representing the 'crystallized' pension rights of staff being transferred to private employers out of their research funds. (The Treasury had been refusing to make extra money available.)

They will also be able to go ahead with plans that had been held up while the review was under way. These include the appointment of new directors to the MRC's Reproductive Laboratory Unit in Edinburgh, and the Dunn Nutrition Unit, which will be 'reconstituted' on moving into a new building next to the university clinical school in Cambridge.

But there was also irritation that results of the prior options exercise, carried out at considerable expense and requiring a substantial effort from the laboratories involved in preparing reports and opening themselves up to assessment, appears in many cases to have resulted in little more than a call for more efficient management.

"This whole process has been dragging on for a long time, and I am pleased to see that the government has realized the problems that it was causing in terms of the loss of morale, and has decided to finish off the matter," says Aaron Klug, president of the Royal Society and the former head of the
MRC's Laboratory of Molecular Biology in Cambridge. "Questioning things is always useful, but not if it involves costly and lengthy procedures."

Klug says that the society, which has expressed concern at the dangers of privatizing bodies that form much of Britain's scientific infrastructure, welcomes the government's announcement that it will in future carry out regular reviews of individual laboratories. "We have been seeking that for a long time. All institutes need to be reviewed to prevent the accumulation of dead wood."

The move to privatize broad chunks of this infrastructure had been promoted by senior government figures, in particular Michael Heseltine, the deputy prime minister. As the former President of the Board of Trade, it was Heseltine who pushed through the transfer to private management of bodies such as the National Physical Laboratory.

But others, including, reportedly, some officials at the Office of Science and Technology - which now forms part of the Department of Trade and Industry - are said to have become increasingly convinced that, whatever the ideological principles involved, the advantages of privatization were outweighed by the potential costs and disruption.

Valerie Ellis, assistant general secretary of the Institution of Professional Managers and Specialists - the labour union that represents many government scientists - says that the decision "vindicates our belief that the whole exercise has been a waste of time and money".

She says that an important factor that may have helped to persuade the government against widespread privatization of its scientific services was its experience over the outbreaks of bovine spongiform encephalopathy and Escherichia coli food poisoning, both of which underlined the need for access to top-level scientific advice.

Labour has promised that if, as is widely expected, it comes to power in the forthcoming general election, it will halt the prioroptions process. Adam Ingram, shadow minister for science and technology, said he welcomed the government's decision to "back off" under pressure from scientists.

But given science's funding difficulties, a Labour government is still expected to have to find ways in which the laboratories can be run more effectively.

If the Conservatives make a surprise comeback, many expect that the privatization campaign will start again. But, with an election looming and pressing decisions being held up, "basically they just ran out of time", says Ellis.

DavidDickson

\section{First national review in Australia looks at 'gaps and overlaps'}

[SYDNEY] A wide-ranging review that could eventually lead to a major reorganization of government-funded science and policy advice has been quietly launched in Australia. Although individual agencies have experienced repeated reviews and restructuring over the past decade, this is the first exercise to look at the national situation.

The review is being carried out by John Stocker, who was recently appointed parttime chief scientist (see Nature 384, 300; 1996). Peter McGauran, science and technology minister, has asked Stocker to report on "any gaps and overlaps in current arrangements" as well as "ways of identifying national priorities".

Stocker says the idea for the initiative came from the National Commission of Audit, set up by John Howard, the Conservative Coalition Prime Minister, after he took office last March. The commission concluded that, with at least seven government portfolios having an interest in science, "there

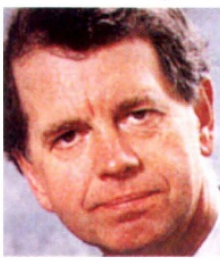

Stocker: reporting by mid-1997.

than a decade ago. McGauran is responsible for the activities of the Commonwealth Scientific and Industrial Research Organization (CSIRO), the Australian Institute of Marine Science and the Australian Nuclear Science and Technology Organization, but not for any of the grantgiving organizations.

Nevertheless, the statutory bodies covering marine and nuclear science, as well as the Australian Geological Survey Organization, are prime targets for being taken into CSIRO. But they will probably not go willingly.

Some advisory bodies could be merged. But the main grant-giving bodies - the Australian Research Council, National Health and Medical Research Council and the Industrial R\&D Board - have solid support within the education, health and industry departments respectively, and are likely to argue strongly against being centralized.

Unusually for national inquiries, the review has started without any public announcement, requests for submissions or public hearings, and is being conducted by one person. It will be completed quickly. Stocker has already contacted key individuals, and says that he has to report to McGauran "by mid-year".
PeterPockley 